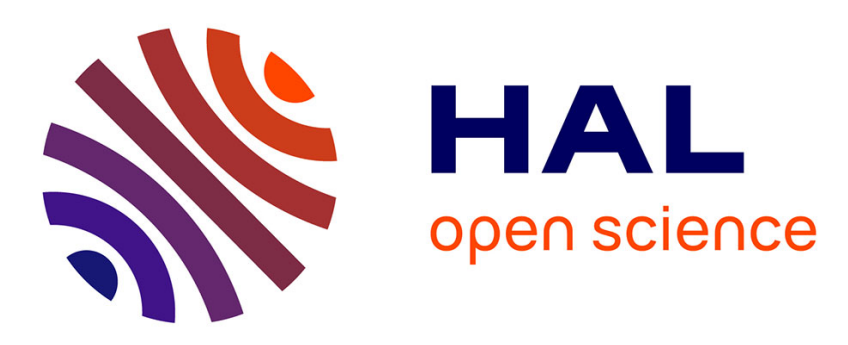

\title{
Experimental study on Combustion modes and thrust performance of a staged-combustor of the scramjet with dual-strut,
} Qingchun Yang, Khaled Chetehouna, Nicolas Gascoin, Wen Bao

\section{- To cite this version:}

Qingchun Yang, Khaled Chetehouna, Nicolas Gascoin, Wen Bao. Experimental study on Combustion modes and thrust performance of a staged-combustor of the scramjet with dual-strut,. Acta Astronautica, 2016. hal-01253275

\section{HAL Id: hal-01253275 \\ https://hal.science/hal-01253275}

Submitted on 19 Feb 2016

HAL is a multi-disciplinary open access archive for the deposit and dissemination of scientific research documents, whether they are published or not. The documents may come from teaching and research institutions in France or abroad, or from public or private research centers.
L'archive ouverte pluridisciplinaire $\mathbf{H A L}$, est destinée au dépôt et à la diffusion de documents scientifiques de niveau recherche, publiés ou non, émanant des établissements d'enseignement et de recherche français ou étrangers, des laboratoires publics ou privés. 


\title{
Experimental study on combustion modes and thrust performance of a staged-combustor of the scramjet with dual-strut
}

\author{
Qingchun Yang, ${ }^{1, a}$ Khaled Chetehouna ${ }^{\mathrm{a}}$, Nicolas Gascoin ${ }^{\mathrm{a}}$ and Wen Bao ${ }^{\mathrm{b}}$ \\ a. Institute National des Sciences Appliquées Centre Val de Loir \\ b. Harbin Institute of Technology, Heilongjiang 150001, People’s Republic of China
}

\begin{abstract}
:
To enable the scramjet operate in a wider flight Mach number, a staged-combustor with dual-strut is introduced to hold more heat release at low flight Mach conditions. The behavior of mode transition was examined using a direct-connect model scramjet experiment along with pressure measurements. The typical operating modes of the staged-combustor are analyzed. Fuel injection scheme has a significant effect on the combustor operating modes, particularly for the supersonic combustion mode. Thrust performances of the combustor with different combustion modes and fuel distributions are reported in this paper. The first-staged strut injection has a better engine performance in the operation of subsonic combustion mode. On the contrast, the second-staged strut injection has a better engine performance in the operation of supersonic combustion mode.
\end{abstract}

Key words: staged-combustor; injection scheme; combustion mode; thrust performance; dual-mode scramjet.

\section{Nomenclature}

$\begin{array}{llll}A & \text { area, } \mathrm{m}^{2} & T & \begin{array}{l}\text { static temperature, } \mathrm{K} \\ \text { total temperature, } \mathrm{K}\end{array} \\ P & \text { Mach number } & T_{t} & \begin{array}{l}\text { ratio of specific heat, } \mathrm{J} /(\mathrm{kg} . \mathrm{k}) \\ \text { fuel equivalence ratio }\end{array} \\ P_{t} & \text { static pressure, } \mathrm{Pa} & \gamma & \\ \begin{array}{l}\text { Subscript } \\ 0\end{array} & \text { total pressure, Pa } & & \text { Injection fuel of downstream strut } \\ 1 & \text { freestream at the inlet entrance } & 2 & \text { Reference point (isolator entrance) }\end{array}$

\section{Introduction}

The supersonic combustion ramjet (scramjet) continues to be the most promising propulsive option for hypersonic flight [1]. In the range of Mach 4 to 8, the scramjet would operate in different combustion modes, including supersonic combustion mode, dual-mode subsonic combustion mode and subsonic combustion mode [2-3]. Selection of combustion modes for different flight conditions has

\footnotetext{
${ }^{1}$ Doctor, Institute National des Sciences Appliquées Centre Val de Loir; Tel:+0033-0754053489, Fax:+ 00330754053489,E-mail: hcmsyang@163.com
} 
significant effects on the combustion stability, thrust performance, inlet unstart and flight control, etc. Optimization selection of combustion modes could offer better performance [4].

In the open literatures, there are many researches have been carried out for the combustion modes of the scramjet. Combustion transition phenomenon and mechanism with inlet Mach number and total temperature, fuel equivalence ratio and wall temperature have been observed and analyzed. Billig [5] firstly demonstrated mode transition in ground tests. By increasing the total temperature of inlet airflow, Sullins [6] experimentally achieved the mode transition. Ryou et al. [7] investigated the effect of combustor length and total temperature on combustion modes, and suggested the minimum combustor length to attain the supersonic or dual-mode combustion. When the combustor side-wall temperature is allowed to rise sufficiently, Matthew [8] experimentally observed the scram-ram mode transition. Cui et al. [9-11] investigated the sudden change and hysteresis phenomenon by introducing the topological rule. Riggins et al. [12] carried out a numerical study and reported that the transition behavior is characterized by the decrease in entropy with an increment of heat release.

When the fuel flow rate is fixed, the fuel distribution may change the combustion mode. Besides, the staged-combustor can effectively avoid the interaction between the inlet and the combustor. The interaction may cause inlet unstart which is a very unstable condition, especially at the low flight Mach number conditions. Sadatake Tomioka et al. [13-15] conduct a series of combustion tests in the stagedcombustor with a strut for the first-stage injection and second-stage wall injectors. Compared to the first injection alone, the maximum thrust increment of the staged-combustor was augmented by $120 \%$. In addition, injection further downstream resulted in low thrust due to the low combustion efficiency. Sirka et al.[16] carried out some experiments on multi-stage supersonic combustion. However, these researches do not mention combustion modes.

Malsur Dharavath et al. [17] studied the fuel-air mixing and combustion in the ethylene fueled scramjet combustor through numerical simulation. The combustor performance is evaluated with a series of struts. But the combustion only occurs in the supersonic combustion mode, it did not report the combustor performance in the subsonic combustion mode. Zhang yan et al.[18] experimentally research the influencing factors on the mode transition in the dual-mode scramjet. Fuel equivalence ratio and fuel and fuel type can change the combustion mode. In Ref[19], the combustion oscillation was investigated experimentally for a cavity combustor. This research divides the flame and combustion into 
three different stages and reports the large-amplitude oscillation with different stages. Wei Huang et al. [20] systematically review the mode transition technique for the combined cycle propulsion engine. It reported that the subsonic/supersonic mode transition can be obtained by varying the fuel equivalence ratio, the wall-heating temperature and so on. Ref [21] reports the experimental results about the detection of different combustion modes. The pressuremagnitude-based detection technique is effective for the scramjet engine

However, there are few researches about combustion modes of a staged supersonic combustor with fuel distributed injection in the scramjet engine. The change of mode transition with the fuel distribution requires further research. The well designed experiments of this paper systematically study the combustion modes and thrust performance in the dualstrut scramjet combustor. The present paper shows that the fuel distribution demonstrates distinctly different influence on the performance under different combustion modes. The firststaged strut injection has a better engine performance in the operation of subsonic combustion mode. However, the second-staged strut injection shows a better performance for supersonic combustion mode. It is great of significance to understand the relations between the combustion modes, thrust performance and the injection distribution for the stagedcombustor.

\section{Experimental apparatus and data reduction}

The current set of results was obtained in the supersonic research facility at the Harbin Institute of Technology, China. A schematic of the experiment can be found in Fig.1. The inlet airflow can be heated to a total temperature of $1250 \mathrm{~K}$ through the alcohol-air combustion. Static pressure of the test inlet air is $158 \mathrm{kPa}$. Additional oxygen is injected to maintain a $0.21 \mathrm{O}_{2}$ mole fraction in the heated products. The heated air enters the isolator section of the experiment at a Mach number of 2. This enables the engine to operate under both supersonic and subsonic combustion modes.

As shown in Fig.1, the staged-combustor includes four segments. The constant area isolator has a $40 \mathrm{~mm} \times 100 \mathrm{~mm}$ cross section. Upstream strut locates in the rear of the isolator. The first-staged combustor includes a divergent section to accommodate the back pressure, and a constant area combustion zone. Geometry of the second-staged combustor is similar to the former. Downstream strut locates in the divergent section of the second-staged combustor. A central strut injector has been employed, which also improve fuel mixing in the supersonic core stream and combustion performance 
in supersonic combustor [22]. Kerosene fuel at room temperature is injected from the strut in the direction normal to the airflow direction. In order to solve the issues associated with thermal protection of the strut, the kerosene injectant serves as active cooling agent and effectively relieves the aerodynamic heating on the thin strut.

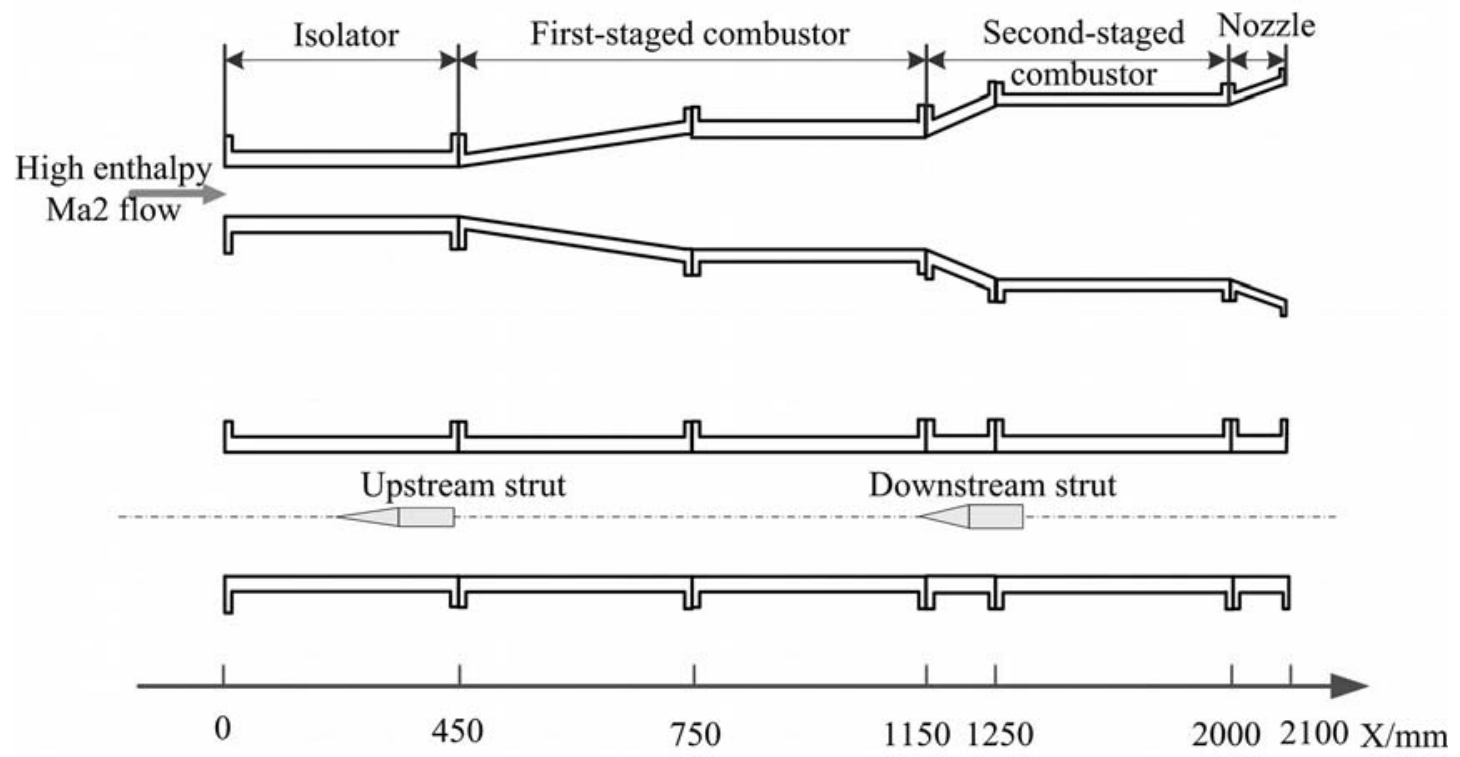

Fig. 1 Schematic diagram of the staged-combustor with dual-strut

To measure the static pressure, pressure-tap ports are distributed on the center line of one side of the combustor wall. Each port is instrumented with a pressure transducer, which are used to measure pressure histories of engine wall pressure. The pressure transducers range $0-1 \mathrm{MPa}$ and error $0.2 \%$ in full scale. The measured results were normalized using the pressure at the entrance of the isolator. The thrust is measured directly. A force measure system (FMS) with single degree of freedom is used to get the joint thrust of the air heater and the scramjet combustor in the direct-connected experiment. A strain gauge force transducer provided by China Academy of Aerospace Aerodynamics is employed in the system. According to the measured pressures, the axial Mach number distribution can be calculated based on one-dimensional model, which has been reported in detail in our previous research [23]. The axial Ma distribution can be used to classify different combustion modes.

\section{Combustion mode definitions in the staged-combustor}

Fig.2 indicates that the Hugoniot curve can be classified as four possible combustion conditions: strong detonation, weak detonation, weak deflagration and strong deflagration $[24,25]$. Within the strong-detonation region, the flow velocity relative to the wave front decreases from supersonic $(M>1)$ to subsonic $(M<1)$. Simultaneously, the pressure and density obviously rise. Within the weak-detonation region, the flow velocity is also decreased through a weak-detonation wave. But the burned flow is still supersonic $(M>1)$. Therefore, 
the supersonic combustion mode and subsonic combustion mode may correspond to the weak-detonation and strong-detonation mode, respectively. Fig.3 shows the flow sketch in the dual mode scramjet engine correspond to different combustion modes.

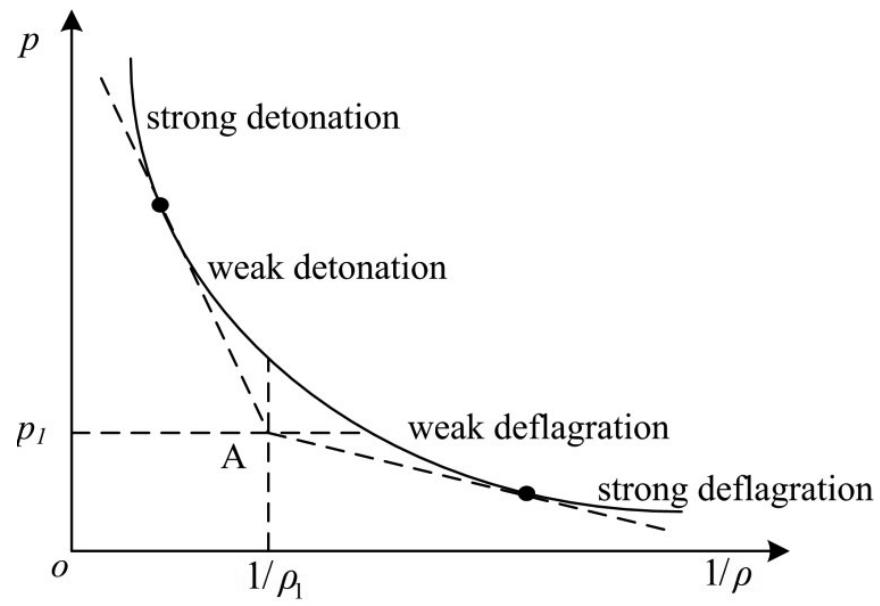

Fig.2 Classification of the Hugoniot curve with different combustion modes

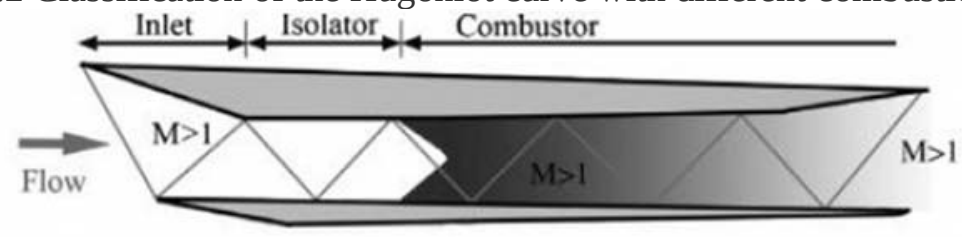

a)supersonic combustion mode

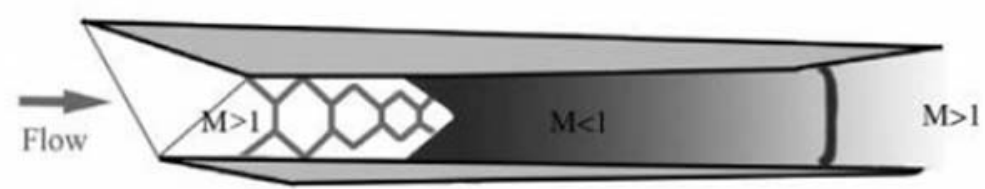

b)subsonic combustion mode

Fig.3 Flow Sketch of the dual-mode scramjet engine

Considering that there will always be a thermal throat at the second stage of combustor with flight

Mach number $M a_{0}=5$, the definitions of combustion modes for the staged-combustor may depend on the flow characteristics at the first-staged combustor. Fig.4 shows three typical pressure and Mach number distributions correspond to three different combustion modes, i.e., supersonic combustion mode, dual-mode subsonic combustion mode and subsonic combustion mode.

1) Supersonic combustion mode. When the first-staged and second-staged fuel equivalence ratios (ER) are 0.15 and 0.3 respectively, the engine operates in the scramjet mode. Because the flow Ma of the first-staged combustor is greater than unity, the back pressure induced by second-staged combustion does not change the upstream combustion mode. Fig. 4 indicates that there is a reflection of wall pressure for the scramjet mode. The pressures show an adverse gradient in the first-staged combustor. 
2) Dual-mode subsonic combustion mode. In the case of $\varphi_{1}=0.4$ and $\varphi_{2}=0.2$, the pressure distribution becomes smoother and A favorable pressure gradient is formed in the last part of the constant area combustion zone. Part of combustion zone $M a$ at the first-staged combustor is smaller than unity. These characteristics demonstrate that the combustor is in the dual-mode subsonic combustion mode.

3) Subsonic combustion mode. As the first-staged fuel ER further increases to 0.5, an intensive combustion takes place in the upstream injector region. The flow of isolator will be disturbed. The back pressure will propagate upstream into isolator. It results in flow separation and wall pressure rise for large parts of the isolator. The whole combustion region $M a$ is blow unity. There are two thermal throat locates at the exit of the first-staged combustor and the second-staged combustor, respectively. The wall pressure appears a favorable gradient and smoother distribution which are the typical characteristics of subsonic combustion mode.

\section{a) Measured wall-pressures}

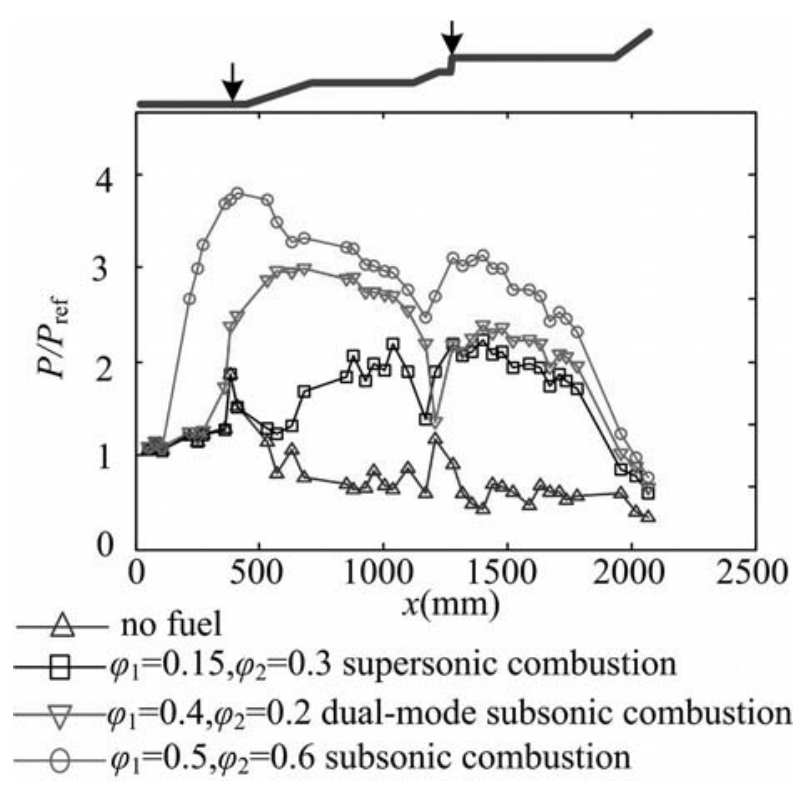

b) Calculated $M a$ 


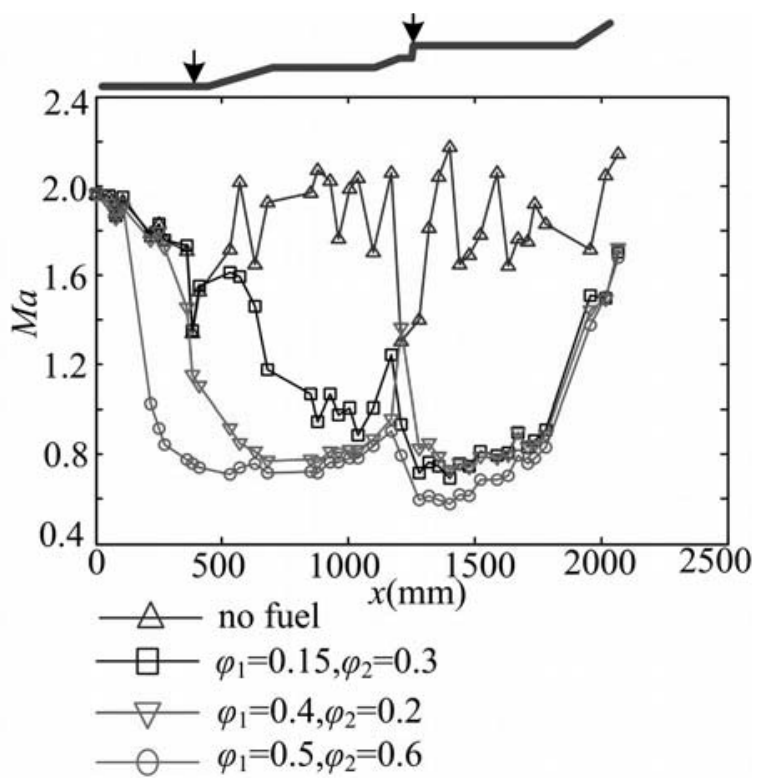

Fig.4 Typical flow parameters axial distribution of the staged-combustor for different

combustion modes

\section{Effect of injection scheme on the combustion modes}

Three typical injection schemes will be reported in this paper, corresponding to three different combustion modes. As the first-staged fuel flow rate increases, the engine will transfer from scramjet mode to dual-mode ramjet mode in flight $M a=5$ situations. The transition process is similar to our previous research in flight $M a=6$ situations. So, in this section, effects of the second-staged fuel on the combustion modes will be experimentally investigated.

As show in Fig.5, the engine will operate in the supersonic combustion mode when the first-staged fuel ER is fixed at $\varphi_{1}=0.15$. While the second-staged fuel ER increases from 0 to 0.7 , the pressure rises at the downstream strut location due to combustion. The back pressure induced by combustion will propagate upstream of the combustor. The lower the first-staged fuel ER is, the greater the impact becomes. As the second-staged ER increases to $\varphi_{1}=0.5$, the engine transfers from scramjet mode to dual-mode scramjet mode. The Mach number at the exit of the first-staged combustor is smaller than unity. However, the pressure in the isolator is not disturbed, avoiding the inlet-isolator interaction. It also indicates that the engine will not operate in the dual-mode ramjet mode even the total ER more than unity. 


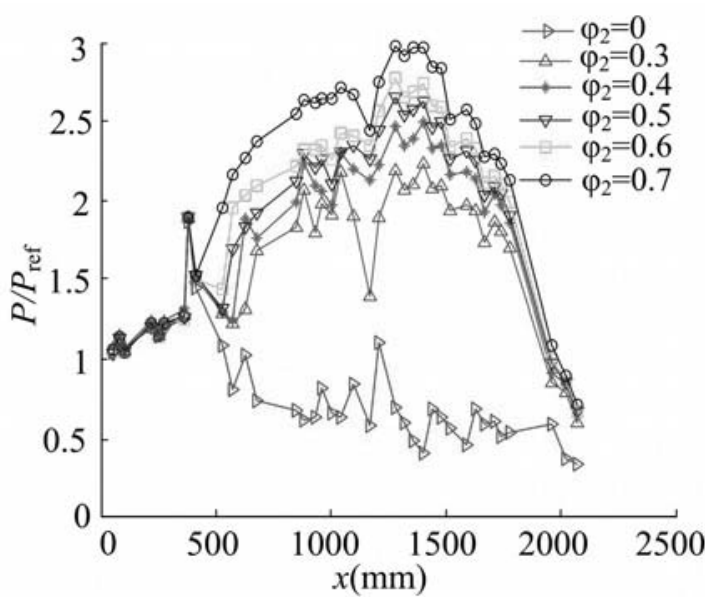

Fig.5 Effect of the second-staged fuel ER on the supersonic combustion modes for $\varphi_{1}=\mathbf{0 . 1 5}$

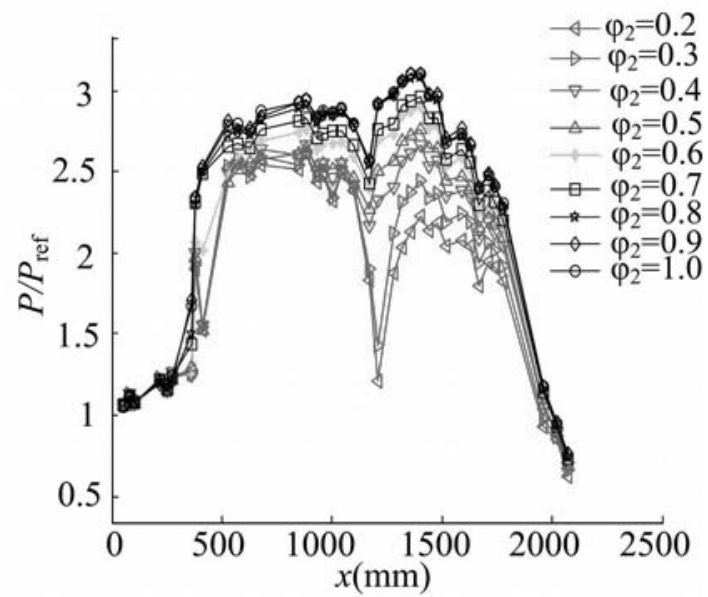

Fig.6 Effect of the second-staged fuel ER on the dual-mode subsonic combustion for $\varphi_{1}=0.3$

Fig. 6 shows the engine operates in the dual-mode subsonic combustion mode when the first-staged fuel ER is fixed at $\varphi_{1}=0.3$. Although the ER increases from 0.2 to 1.0 , the engine still operates in the dual-mode scramjet mode. The pressure gradient of the first-staged combustor does not change. Fig. 6 also demonstrates that the second-staged fuel cannot change the operation mode of the engine. When the second-staged fuel further increases, Fig.7 indicates that there is little change in the first-staged pressure for subsonic combustion mode. Because the second-staged back pressure is significantly lower than the first-staged, it cannot propagate upstream. Correspondingly, the engine still operates in the subsonic combustion mode.

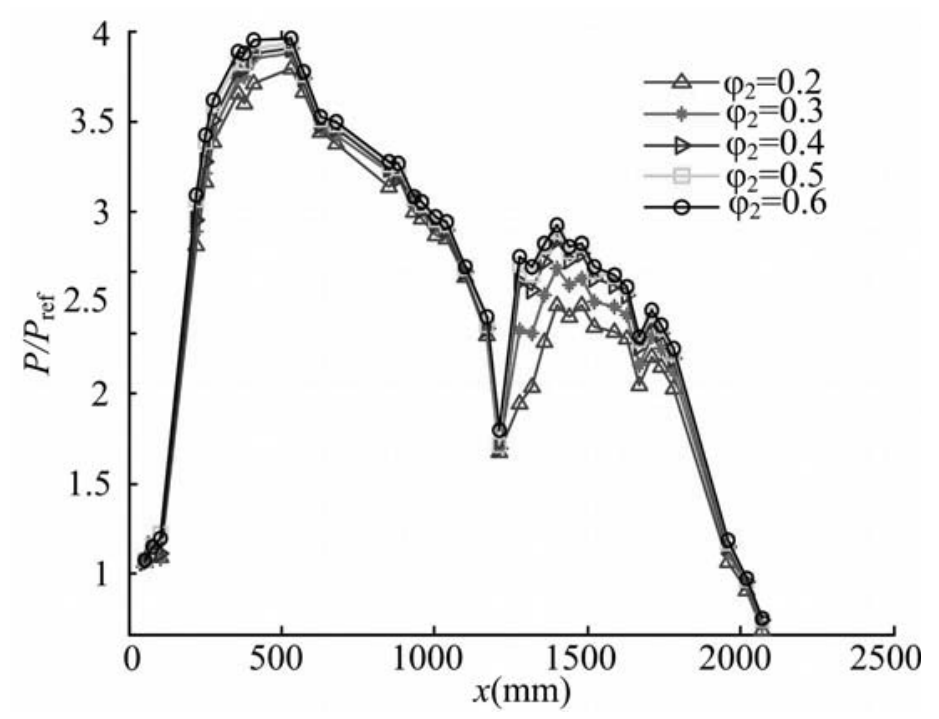

Fig.7 Effect of the second-staged fuel ER on the subsonic combustion modes for $\left(\varphi_{1}=0.6\right)$ 


\section{Thrust performance of the staged-combustor with different combustion mode}

To study the thrust performance with different combustion mode, the total fuel ER keep constant for a single test. But the distribution of fuel between the first-staged injector and second-staged injector is varied. The total ER ranges 0.6 1.2. As the total ER is fixed, Fig.8 shows relations between the engine thrust and the fuel distribution. Due to the limitation of inlet-combustor interaction, the firststaged fuel ER is less than 0.6. However, the second-staged ER is unrestricted, considering that it does not disturb the pressure of isolator.

As shown in Fig.8, the engine thrust significantly increases with an increase in the first-staged fuel for the subsonic combustion mode. For comparison, the engine thrust, for supersonic combustion mode, decreases with the increase of the first-staged fuel flow rate. While the first-staged fuel ER increases from 0.3 to 0.35 , the engine transfers from supersonic combustion mode to dual-mode subsonic combustion mode. Therefore, as the total fuel ER is fixed at $\varphi_{\mathrm{t}}=0.6$, the thrust will reach a turning-point with the critical point of mode transition. It should be noted that the experimental data for the scramjet mode is relatively few, because the scope of scramjet mode is very narrow with flight Mach number $M a_{0}=5$. Not only the first-staged fuel, but also the second-staged fuel will also affect the supersonic combustion mode.

a) Dual-mode subsonic combustion mode/subsonic combustion mode

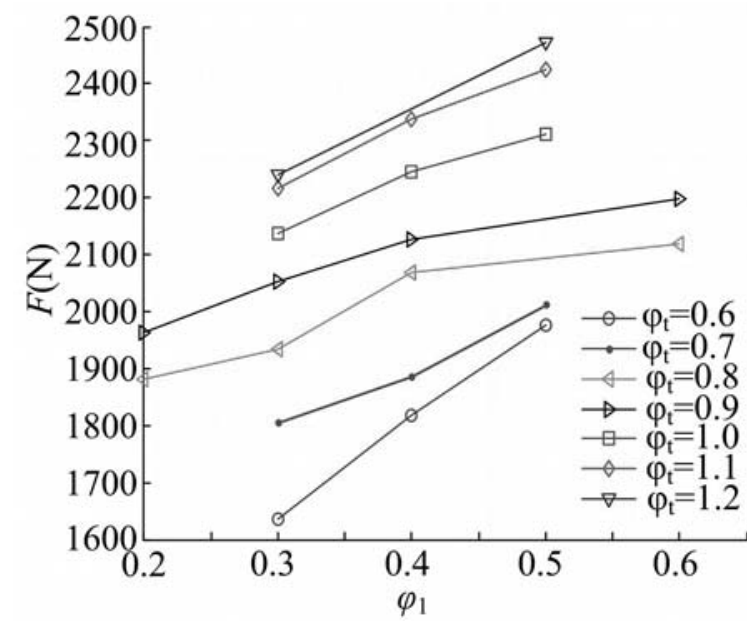

b) Supersonic combustion mode 


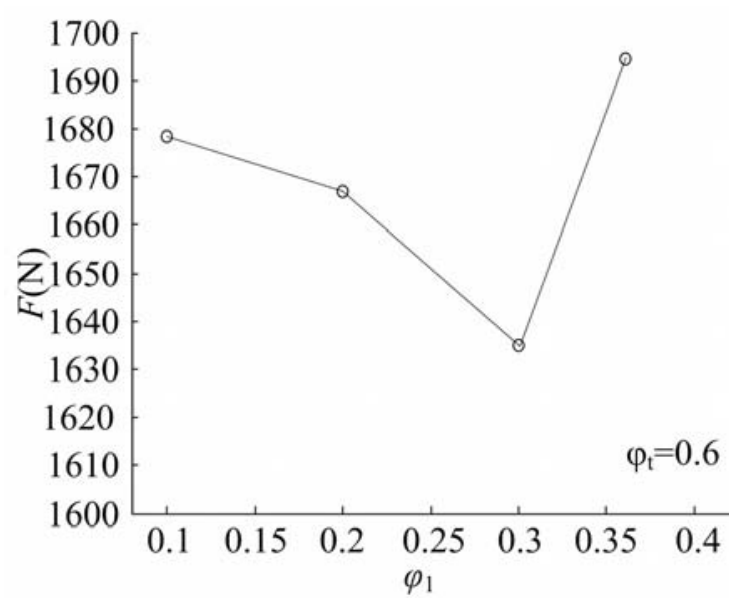

Fig. 8 Variation of the engine thrust with the first-staged fuel equivalence ratio under the

\section{condition of the same total ER}

In order to explain the experimental results in Fig.8, Fig.9 shows the comparisons of wall pressure distribution for $\varphi_{\mathrm{t}}=0.6$. Under the dual-mode subsonic combustion mode, it may be observed that wall pressures of the first divergent section significantly rise while the first-staged ER increases from 0.3 to 0.4, correspondingly the second-staged ER decreases from 0.3 to 0.2 . An intensive combustion forms at further upstream location. A large pressure rise with combustion causes the flow separation near the first strut and the second-staged pressures almost keep constant. So, it results in larger flow $M a$ decrease.

As a result of energy release, the decrease of total pressure is usually referred to as "Rayleigh heating loss”. It should be noted that the energy release occurs in the constant-area combustor, i.e.

$$
d A=0
$$

Then, the one-dimensional flow equations for the conservation of mass, momentum and energy can be assembled blow for the constant area combustor without frictionless.

$$
\left\{\begin{array}{l}
\frac{d \rho}{\rho}+\frac{d V}{V}=0 \\
\frac{d P}{P}+\gamma M^{2} \frac{d V}{V}=0 \\
\frac{d T_{t}}{T}-\frac{d T}{T}-(\gamma-1) M^{2} \frac{d V}{V}=0
\end{array}\right.
$$

The relationship between the total pressure $P_{\mathrm{t}}$ and the static pressure $P$ is defined as

$$
P_{t}=P\left(1+\frac{\gamma-1}{2} M^{2}\right)^{\frac{\gamma}{\gamma-1}}
$$


It can be stated in differential form,

$$
\frac{d P_{t}}{P_{t}}=\frac{d P}{P}+\frac{\gamma M d M}{1+\frac{\gamma-1}{2} M^{2}}
$$

Finally, through substituting equation (2) and equation (4), the total pressure loss due to heat addition can be obtained as shown below.

$$
\frac{d P_{t}}{P_{t}}=-\frac{\gamma M^{2}}{2} \frac{d T_{t}}{T_{t}}
$$

The total pressure loss is an important performance parameter for the design of combustor. In general, the loss in total pressure should be less than 60 percent in the practical scramjet combustor.

Eq. (5) means that the total pressure always decreases with increased heating (or total temperature), and more rapidly as the Mach number of the combustion increases. Therefore, the decrease of flow Ma reduces the total pressure loss. Correspondingly, it will improve the engine performance. As shown in Fig.9b, when the second-staged fuel ER increases from 0.3 to 0.5 with scramjet mode, a larger pressure rise takes place near the downstream strut. So, it results in a larger total pressure recovery coefficient. In conclusion, the concentration of heat release can effectively increase the engine performance.

a) Dual-mode subsonic combustion mode

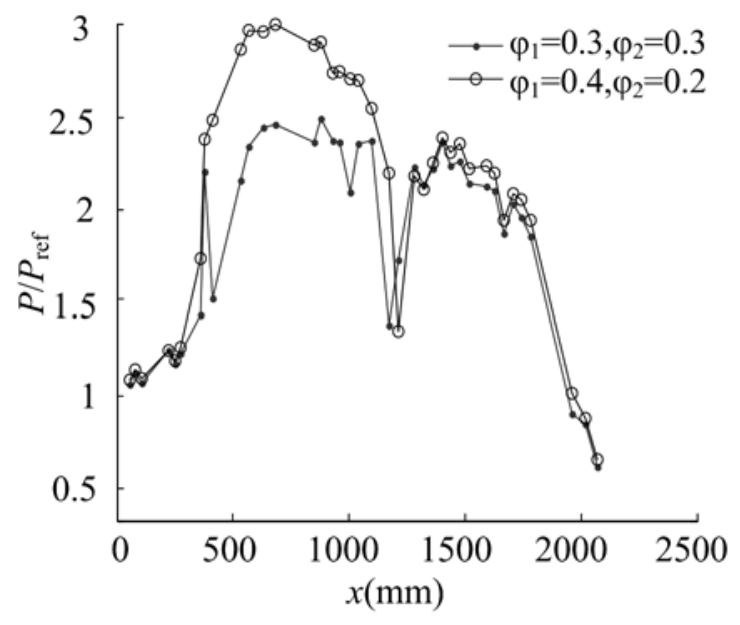

b) supersonic combustion mode 


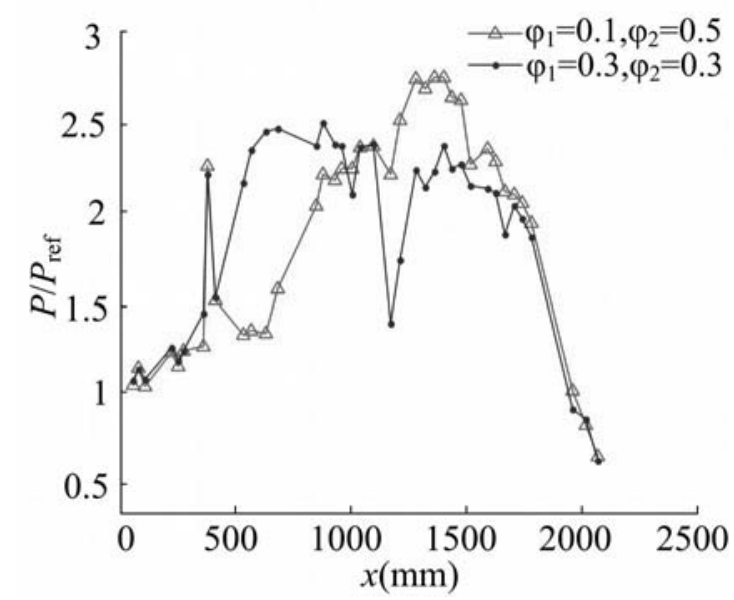

Fig.9 Effect of fuel distributions on the wall pressures for different combustion modes

\section{Conclusion}

Combustion experiments of the staged-combustor were conducted under the incoming $M a 2$ airflow conditions with a total temperature of $1250 \mathrm{~K}$ and a static pressure $158 \mathrm{kPa}$. The upstream strut locates at the rear of isolator and that of downstream locates at the second-staged combustor. The following results are forthcoming:

1) According to the flow characteristics of the first-staged combustor, the staged-combustor can be divided into three different combustion modes. Combustion of the second-staged combustor is always subsonic.

2) The second-staged combustion could affect the first-staged combustion mode. When the engine operates in the supersonic combustion mode, the second-staged fuel can lead to mode transition. But, it cannot change the dual-mode subsonic combustion mode, only raise the wall pressures slightly. For the subsonic combustion mode, the first-staged wall pressures almost keep constant with the increase of the second-staged fuel.

3) The thrust performance of combustor depends on the combustion mode. Under the supersonic combustion mode, the increase of the second-staged fuel flow rate can offer better performance. In contrary, the increase of the first-staged fuel can offer better performance in the operation of subsonic combustion mode.

\section{References}

[1] Moses, Paul L., et al. "NASA hypersonic flight demonstrators-overview, status, and future plans." Acta Astronautica 55.3 (2004): 619-630. 
[2] Tian, Lu, et al. "Quasi-One-Dimensional Multimodes Analysis for Dual-Mode Scramjet." Journal of Propulsion and Power 30.6 (2014): 1559-1567.

[3] Torrez, Sean M., et al. "A scramjet engine model including effects of precombustion shocks and dissociation." AIAA Paper 4619 (2008): 2008.

[4] Cao, Ruifeng, et al. "Analysis of combustion mode and operating route for hydrogen fueled scramjet engine." International Journal of Hydrogen Energy 38.14 (2013): 5928-5935.

[5] Billig, Frederick S. "Combustion processes in supersonic flow." Journal of Propulsion and Power 4.3 (1988): 209-216.

[6] Sullins, G. A. "Demonstration of mode transition in a scramjet combustor." Journal of Propulsion and Power 9.4 (1993): 515-520.

[7] Masumoto, Ryou, et al. "Experimental study on combustion modes in a supersonic combustor." Journal of Propulsion and Power 27.2 (2011): 346-355.

[8] Fotia, Matthew L., and James F. Driscoll. "Ram-scram transition and flame/shock-train interactions in a model scramjet experiment." Journal of Propulsion and Power 29.1 (2013): 261-273.

[9] Cui, Tao, et al. "Hysteresis Phenomenon of Mode Transition in Ramjet Engines and Its Topological Rules." Journal of Propulsion and Power 28.6 (2012): 1277-1284.

[10] Cui, Tao, Yong Wang, and Daren Yu. "Bistability and Hysteresis in a Nonlinear Dynamic Model of Shock Motion." Journal of Aircraft 51.5 (2014): 1373-1379.

[11] Cui, Tao, Zhong Lv, and Daren Yu. "Multistability and Complex Routes of Supersonic Inlet Start/Unstart." Journal of Propulsion and Power 27.6 (2011): 1204-1217.

[12] Riggins, David, et al. "Thermodynamic analysis of dual-mode scramjet engine operation and performance." AIAA Paper 8059 (2006): 2006.

[13] Tomioka, Sadatake, et al. "Effects of injection scheme on performance of a staged supersonic combustor." AIAA paper (1999): 99-2107.

[14] Tomioka, Sadatake, et al. "Combustion tests of a staged supersonic combustor with a strut." Journal of Propulsion and Power 17.2 (2001): 293-300.

[15] Tomioka, Sadatake, et al. "Distributed fuel injection for performance improvement of staged supersonic combustor." Journal of propulsion and power 21.4 (2005): 760-763.

[16] Fuhrmann, Sirka, Andreas Hupfer, and Hans-Peter Kau. "Investigations on multi-stage supersonic combustion in a model combustor." 17th International Space Planes and Hypersonic systems and Technologies Conference, San Francisco, California, USA. 2011. 
[17] Dharavath, M., Manna, P., \& Chakraborty, D. (2015). Numerical exploration of mixing and combustion in ethylene fueled scramjet combustor. Acta Astronautica, 117, 305-318.

[18] Yan, Z., Bing, C., Gang, L., Baoxi, W., \& Xu, X. (2014). Influencing factors on the mode transition in a dual-mode scramjet. Acta Astronautica, 103, 1-15.

[19] Ouyang, H., Liu, W., \& Sun, M. (2015). The large-amplitude combustion oscillation in a single-side expansion scramjet combustor. Acta Astronautica, 117, 90-98.

[20] Huang, W., Yan, L., \& Tan, J. G. (2014). Survey on the mode transition technique in combined cycle propulsion systems. Aerospace Science and Technology, 39, 685-691.

[21] Zhang, C., Yang, Q., Chang, J., Tang, J., \& Bao, W. (2015). Nonlinear characteristics and detection of combustion modes for a hydrocarbon fueled scramjet. Acta Astronautica, 110, 8998.

[22] Rust, Benjamin, et al. "Numerical simulation of the internal and external flowfields of a scramjet fuel strut injector including conjugate heat transfer." Proceedings of the 17th AIAA International Space Planes and Hypersonic Systems and Technologies Conference. 2011.

[23] Bao, Wen, et al. "Dynamic characteristics of combustion mode transitions in a strut-based scramjet combustor model." Journal of Propulsion and Power 29.5 (2013): 1244-1248.

[24] Smirnov, N. N., Betelin, V. B., Nikitin, V. F., Phylippov, Y. G., \& Koo, J. (2014). Detonation engine fed by acetylene-oxygen mixture. Acta Astronautica, 104(1), 134-146.

[25] Smirnov, N. N., Nikitin, V. F., \& Phylippov, Y. G. (2010). Deflagration-to-detonation transition in gases in tubes with cavities. Journal of Engineering Physics and Thermophysics, 83(6), 1287-1316. 
1. The staged-combustor with dual-strut is introduced to avoid inlet-combustor interaction.

2. Fuel injection scheme has a significant effect on the staged-combustor operating modes

3. Thrust with different combustion mode is reported through staged-combustor experiments. 